\title{
РОЖДАЕМОСТЬ В РЕСПУБЛИКЕ МОЛДОВА: ЕВРОПЕЙСКИЕ ТЕНДЕНЦИИ И НАЦИОНАЛЬНАЯ СПЕЦИФИКА
}

\author{
ОЛЬГА ГАГАУЗ
}

В настоящее время официальная статистика Республики Молдова, основываясь на данных о численности населения dе јиге (включая граждан, отсутствующих в стране 12 месячев и более), дает заниженные оценки коэффициента суммарной рождаемости, что привело к отнесению страны к группе стран со сверхнизким уровнем рождаемости (lowest-low fertility).

На основе данных о численности населения de facto, а также результатов Переписи населения и жилищ 2014 2. анализируются уровень и основные тенденции в динамике рождаемости в разрезе условных и реальных поколений. Основная цель исследования - проследить, до какого уровня снизилась рождаемость в Республике Молдова и можно ли ее относить к странам с низкой или очень низкой рождаемостью (low fertility or lowest-low fertility).

Результаты исследования показывают, что трансформаџия рождаемости происходит согласно общей модели, характерной для большинства стран, завершивших или находящихся в проиессе перехода рождаемости, однако характеризуется более низкими темпами. Для условных поколений рождаемость установилась на уровне 1,6-1,65 рождений на одну женщину, тогда как для реальных поколений, завершивших или находящихся на стадии завершения репродуктивного периода - на уровне 1,9-2,0 рождения. Даже для самых молодых поколений, достигших на момент переписи 35-летнего возраста (2014 2.), среднее число рожденных детей превысило значение 1,7. Несмотря на то, что в межпереписной период наблюдается сокращение среднего числа рождений к кониу репродуктивного периода, среднее число рождений у женщин к 50-летнему возрасту составляет 2,1, а доля тех, кто не родил ни одного ребенка сохраняется на относительно низком уровне.

Основываясь на результатах исследования, автор делает вывод, что Республика Молдова не относится к странам с низкой или очень низкой рождаемостью (low fertility or lowest-low fertility), a coxранение более высокого уровня рождаемости по сравнению с другими странами определяется преобладанием сельских жителей в общей структуре населения.

Ключевые слова: рождаемость, Республика Молдова, условные поколения, реальные поколения, возрастной профиль рождаемости, средний возраст матери при рождении, суммарная рождаемость.

\section{ВВЕДЕНИЕ}

Исследованию рождаемости по-прежнему уделяется много внимания, ведется активный поиск объяснительных моделей снижения рождаемости, определения общего и особенного в динамике рождаемости стран, завершивших второй демографический переход, находящихся на его начальном этапе или в самом его разгаре. Сформирован солидный теоретико-методологический аппарат, накоплен достаточно большой опыт эмпирических исследований, значительно усовершенствованы методы демографического анализа рождаемости, что позволяет проводить глубокий и всесторонний анализ изменений рождаемости.

ОЛЬГА ЕВСЕЕВНА ГАГАУЗ (gagauzo@inbox.ru), НАЦИОНАЛЬНЫЙ ИНСТИТУТ ЭКОНОМИЧЕСКИХ ИССЛЕДОВАНИЙ, РЕСПУБЛИКА МОЛДОВА.

СТАТЬЯ ПОСТУПИЛА В РЕДАКЦИЮ В ИЮНЕ 2018 Г. 
Республика Молдова, как и другие страны, бывшие республики СССР, столкнулась с существенными проблемами в области демографического развития. Быстрое сокращение численности населения и углубление процесса демографического старения как результат сокращения рождаемости и массовой миграции представляют серьезную угрозу для достижения устойчивого социально-экономического развития. В связи с этим правительством страны была принята Национальная программа в области демографической безопасности на 2011-2025 гг., предусматривающая комплексные меры, направленные на улучшение демографической ситуации.

Наибольшее внимание и озабоченность привлекает сокращение рождаемости, ее абсолютные и относительные показатели, все чаще раздаются призывы политиков к необходимости принятия мер по повышению рождаемости и увеличению числа детей в семье. Определенную роль в этом плане играют данные официальной статистики, согласно которым в 2000-2016 гг. коэффициент суммарной рождаемости (КСР) составлял 1,2-1,3 живорождений на одну женщину, что не соответствует реальной ситуации, а обусловлено используемой методикой расчета данного показателя.

Известно, что с конца 90-х годов Республика Молдова характеризуется высокой территориальной подвижностью населения, а потоки мигрантов с некоторыми колебаниями увеличивались из года в год. Вместе с тем учет миграции сопряжен с некоторыми проблемами. Так, официальная статистика эмиграции основана исключительно на информации, полученной из специальной формы регистрации. Граждане страны попадают в статистику как эмигранты только в том случае, когда они сняты с учета со своего постоянного (официального) места проживания. Это положение в официальной статистике фигурирует под названием «задокументированная» эмиграция. Граждане Республики Молдова, выехавшие за рубеж в поисках работы и проживающие там длительный период (12 месяцев и более), но имеющие постоянное место жительства в стране, считаются временными эмигрантами и относятся статистикой к «временной» или «рабочей» эмиграции. Таким образом, в численность населения Республики Молдова включены все граждане, в том числе и выехавшие когда-то за границу, но не снявшиеся с учета с постоянного места жительства, так называемое население de jure. Bce социальноэкономические и демографические показатели рассчитываются по отношению к населению de jure, что привело к значительному их искажению, некоторые показатели занижены, другие завышены. Так как по настоящее время число граждан, покинувших страну, составляет около 20\% (таблица 1), то разница между показателями, рассчитанными для населения de jure и наличного населения (резидентов, населения de facto), достаточно значительна.

Сложившаяся ситуация с учетом миграции и использование в качестве знаменателя численности населения de jure привели к тому, что на протяжении многих лет оценки КСР являются заниженными, что вводит в заблуждение как исследователей, так и тех, кто занимается разработкой политики. Основываясь на данных Национального бюро статистики (НБС), международных организаций, также отражающих официальные данные, исследователи относят Республику Молдову к странам со сверхнизким уровнем рождаемости (lowest-low fertility) [Архангельский 2018; Щербакова 2016]. 
Следует отметить, что данная проблема поднималась научным сообществом, были сделаны оценки численности наличного населения на основе текущей статистики НБС и различных источников по статистике миграции [Penina, Jdanov, Grigoriev 2015], а также были сделаны переоценки показателей рождаемости для календарных лет, некоторые оценки и прогнозы итоговой рождаемости реальных поколений [Gagauz 2016]. Кроме того, европейский проект Human Fertility Database предоставил оценки основных показателей рождаемости для Республики Молдова (Human Fertility Collection), рассчитанных для наличного населения, что способствовало доступу исследователей к более надежным данным.

Проведение Переписи населения и жилищ в 2014 г. (ПНЖ 2014) позволило получить важную информацию, в первую очередь, о численности наличного населения, а также о важных структурных характеристиках, касающихся рождаемости. Следует отметить, что переписи населения, проведенные в годы независимости Республики Молдова, сохранили важный вопрос, адресованный женщинам, о числе детей, рожденных живыми, что позволяет получить ценные данные об изменении рождаемости, в том числе в зависимости от различных социально-демографических характеристик женщин (года рождения, этнической принадлежности, уровня образования). Доступность новых данных открыла возможность для более детального анализа рождаемости и послужила основой для данного исследования.

В статье представлены основные тенденции изменения рождаемости в Республике Молдова в период после 1990 г., проанализированы особенности трансформации ее возрастной модели. Основываясь на исследовании рождаемости условных и реальных поколений, автор пытается ответить на один из важных вопросов: до какого уровня снизилась рождаемость в Республике Молдова и можно ли ее относить к странам с низкой или очень низкой рождаемостью (low fertility or lowest-low fertility).

\section{ДАННЫЕ И МЕТОДЫ ИССЛЕДОВАНИЯ}

Для исследования были использованы различные источники данных.

- В качестве данных о численности женщин репродуктивного возраста (население под риском) по однолетним возрастным группам использовались данные переписей населения 2004 и 2014 г., а также оценки численности населения de facto [Penina, Jdanov, Grigoriev 2015].

- Данные переписей 2004 и 2014 г. о числе рожденных детей по однолетним возрастным группам женщин.

- Данные текущей статистики о числе рождений по возрасту матери для однолетних возрастных групп.

- Расчеты автора для однолетних когорт 1960-1975 годов рождения, основанные на ежегодных данных о рождениях, зарегистрированных в органах ЗАГС, и оценках численности женщин (de facto) по однолетним возрастным группам.

Исследование основывается на классических методах демографического анализа рождаемости, в частности на всестороннем сравнительном анализе возрастных и 
кумулятивных коэффициентов рождаемости для условных и реальных поколений в разрезе однолетних возрастных групп.

Следует отметить проблему качества данных. Одной из основных по-прежнему остается проблема определения численности наличного населения Республики Молдова. Перепись населения и жилищ 2014 г. проходила в сложных социально-экономических и политических условиях, оказавших негативное влияние на ее организацию и проведение, соответственно и на результаты. В столице (г. Кишиневе) переписью было охвачено только 59\% населения, в других административно-территориальных единицах - 91\%. По данным переписи и дооценкам численности населения, сделанным на основе административных источников, население Республики Молдова составило 2998,2 тыс., в том числе 2789,2 тыс. - население с обычным местом жительства (резиденты, население de facto, население под риском). Следует отметить, что по оценкам исследователей [Penina, Jdanov, Grigoriev 2015] численность населения с обычным местом жительства (de facto) на 1 января 2014 г. составила 2911,6 тыс., на 122,4 тыс. (или на 4,2 п.п.) больше, чем по данным переписи (таблица 1), что указывает на относительно высокий уровень достоверности оценок численности населения, используемых в данном исследовании для расчета показателей рождаемости.

Таблица 1. Численность населения Республики Молдова по данным переписей 2004 и 2014 г., альтернативным оценкам и текущей статистике, тыс. человек

\begin{tabular}{l|c|c|c|c|c}
\hline & 2004 & $\begin{array}{c}2014 \\
\text { (перепись) }\end{array}$ & $\begin{array}{c}2014 \\
\text { (перепись }+ \\
\text { дооценки) }\end{array}$ & $\begin{array}{c}2014 \\
\text { оценки* }\end{array}$ & $\begin{array}{c}2014 \\
\text { НБС, население } \\
\text { de јure }\end{array}$ \\
\hline $\begin{array}{l}\text { Все население } \\
\text { включая: }\end{array}$ & 3383,3 & 2804,8 & 2998,2 & 2911,6 & 3556,4 \\
резидентов & - & 2595,7 & 2789,2 & 2911,6 & 3413,2 \\
нерезидентов & - & 209,0 & 209,0 & - & 143,2 \\
\hline
\end{tabular}

Источник: Данные НБС, *-[Penina, Jdanov, Grigoriev 2015].

Примечание: Без Приднестровья и Муницииия Бендеры.

Что касается данных о числе рождений для календарных лет, то и в этом плане существуют некоторые проблемы полноты данных за последние несколько лет. Это связано с тем, что из года в год увеличивается численность населения, имеющего двойное гражданство - Республики Молдова и Румынии ${ }^{1}$, что в свою очередь ведет к регистрации некоторого числа новорожденных в консульстве Румынии. В течение последних нескольких лет число новорожденных согласно данным медицинских учреждений превышает число новорожденных, зарегистрированных в органах ЗАГС, примерно на 5\% (официальная статистика рождаемости основывается на данных о новорождённых, зарегистрированных в органах ЗАГС).

\section{ТРАНСФОРМАЦИЯ УРОВНЯ И ВОЗРАСТНОГО ПРОФИЛЯ РОЖДАЕМОСТИ}

Причины и факторы, обусловившие снижение рождаемости в странах восточной Европы, к

\footnotetext{
${ }^{1}$ По данным ПНЖ 2014 г. 176 тыс. (6,3\% населения) обладают гражданством Румынии.
} 
которым относится и Республика Молдова, широко обсуждались в научной литературе. Первоначально преобладали исследования, демонстрирующие определяющее влияние экономического кризиса 1990-х годов и социальной аномии [Billingsley 2010; Perelli-Harris 2008], затем все большее распространение и обоснование получили выводы о влиянии западных ценностей и идеологии, связанных со вторым демографическим переходом [Фрейка, Захаров 2014; Sobotka 2008, 2011; Zakharov 2008]. Однако эти два подхода не являются взаимоисключающими, экономический кризис и культурная диффузия оказывали одновременное влияние. Формирование рыночных отношений и демократических институтов по западному образцу послужили основой для изменения условий формирования семьи и деторождения, а также распространения норм, ценностей и установок западного типа демографического поведения [Frejka 2008].

Все большее распространение получило научное мнение о том, что изменение демографического поведения в большинстве европейских стран будет развиваться одинаково, но конвергенция будет достигнута в долгосрочной перспективе [Kuijsten 1996], в то время как расхождения (дивергенция) будут определяться разницей, касающейся дебюта демографического перехода, скоростью его развития [Fokkema, Liefbroer 2008], а также экономическими, культурными и институциональными особенностями [Frejka, Sobotka 2008].

Исследования показывают, что откладывание рождений на более поздний период и повышение возраста материнства ведут к низкой рождаемости и чрезвычайно низкой рождаемости (low fertility, lowest-low fertility), регистрируемой для календарных лет [Kohler, Billari, Ortega 2002; McDonald 2008; Sobotka 2017].

Изменение рождаемости в Республике Молдова следует общеевропейским тенденциям, будучи особенно близким по своим характеристикам к странам - бывшим советским республикам [Sobotka 2003; Гагауз 2011, 2012, 2013]. Как и другие страны центральной и восточной Европы, Республика Молдова вступила в фазу второго демографического перехода с середины 90-х годов XX века, а в эволюции рождаемости появились новые тенденции, раннее не характерные для страны. Резкое сокращение КСР сопровождалось снижением рождаемости в самых молодых возрастных группах матерей и постепенным увеличением вклада в итоговую рождаемость старших возрастных групп, повышением среднего возраста женщин при вступлении в первый брак и при рождении первого ребенка, распространением партнерских союзов и внебрачных рождений.

Трансформация рождаемости в Республике Молдова происходит согласно общей модели [Frejka 2012], характерной для большинства стран, завершивших или находящихся в процессе перехода рождаемости (fertility transition). Так, на начальном этапе КСР снизился до своего исторического минимума - 1,44 рождений на одну женщину в 2002 г., затем начался медленный рост рождаемости как результат реализации отложенных рождений в предыдущий период (в молодых возрастах). В последние годы с некоторыми колебаниями КСР стабилизировался на уровне 1,6-1,65 рождений на одну женщину. 


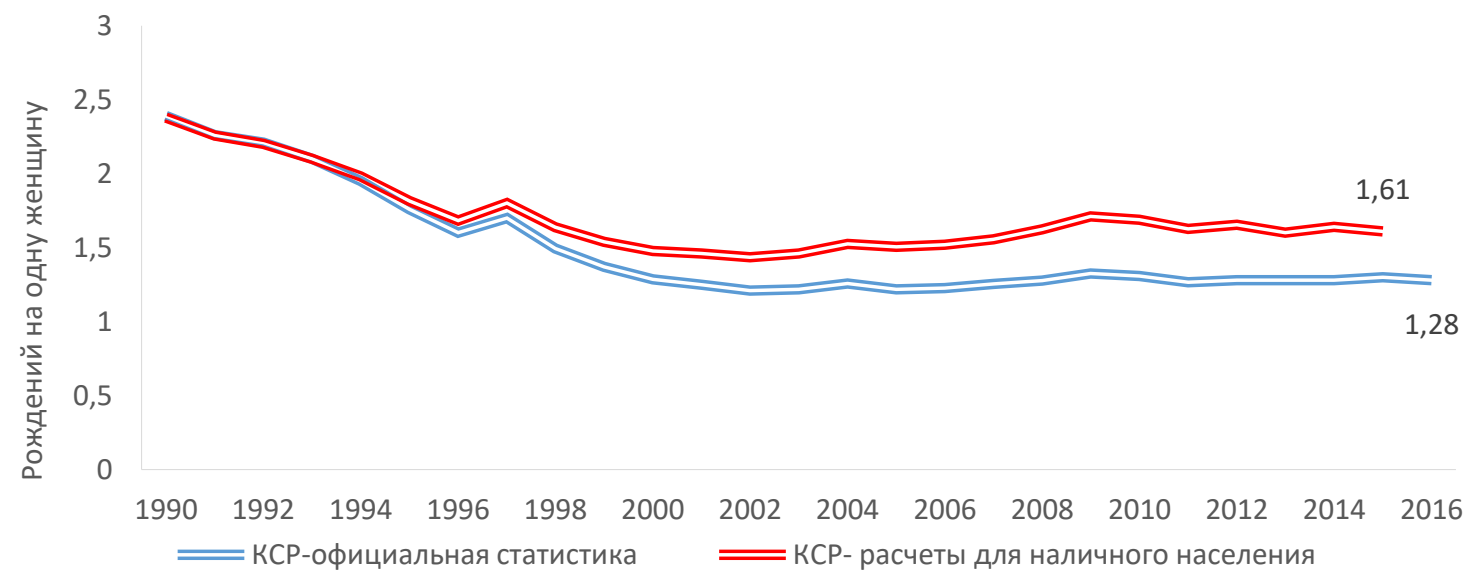

Рисунок 1. Коэффициент суммарной рождаемости, 1990-2016 гг. (различные оценки)

Источник: Расчеть автора.

Примечание: С 1998 г. без Приднестровья и Мунищипия Бендеры.

Следуя общим тенденциям перестройки рождаемости, снижение КСР сопровождается изменением ее возрастного профиля. За последнее десятилетие кривые рождаемости сместились к более поздним возрастам и потеряли свою островершинность, указывавшую на концентрацию рождений в молодых возрастах, как это было еще в 2000 и 2004 гг. (рисунок 2). Впервые возрастные коэффициенты рождаемости в возрастной группе 25-29 лет превысили значения 20-24-летних в 2008 г., однако разница между показателями этих возрастных групп небольшая, более того, наблюдаются их некоторые колебания в сторону увеличения/уменьшения, что говорит о переходном профиле рождаемости - от молодого к более позднему. Вместе с тем ярким свидетельством постарения материнства является увеличение (примерно в два раза по сравнению с 2000 г.) возрастных коэффициентов рождаемости в возрастных группах 30-34 и 35-39 лет.

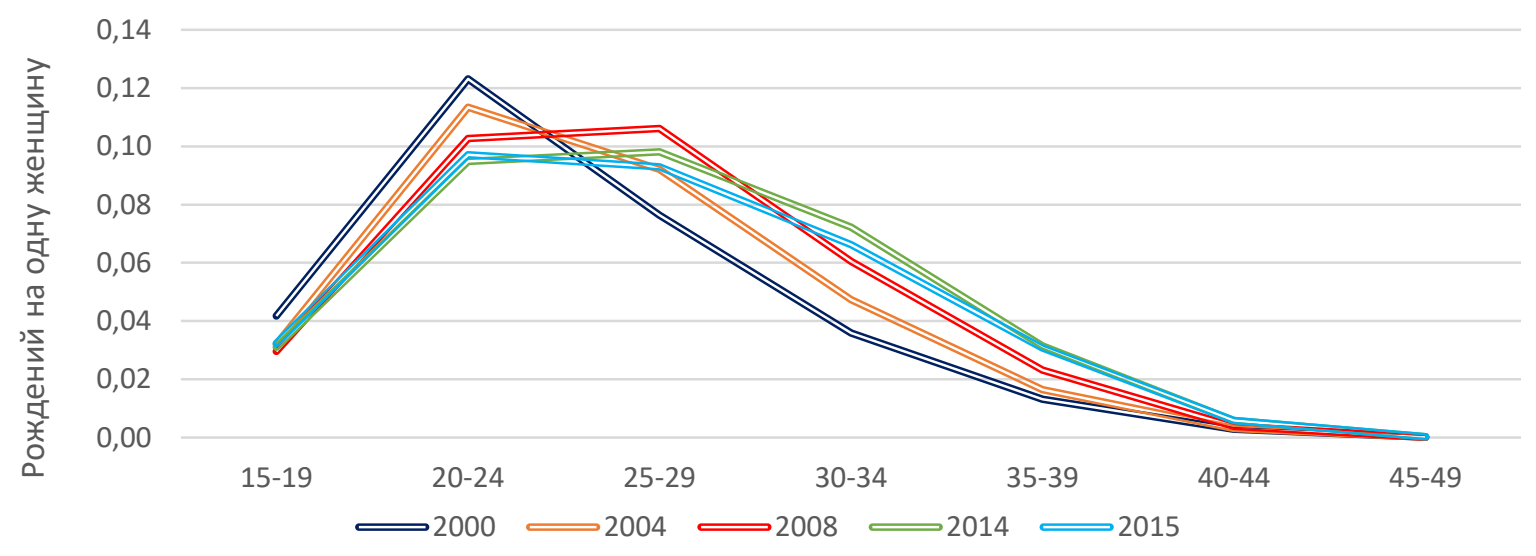

Рисунок 2. Возрастные показатели рождаемости, 2000-2015

Источник: Расчеты автора на основе данных статистики о рождениях и численности наличного населения.

Примечание: Без Приднестровья и Муниципия Бендеры.

Перестройка календаря рождений и откладывание материнства на более поздний период ведет к повышению среднего возраста матери при рождении всех очерёдностей и 
при рождении первого ребенка. Начиная с 1995 г. наблюдается устойчивая тенденция роста этих показателей, среднегодовое увеличение среднего возраста матери при рождении первого ребенка составило 0,1-0,2 года, а за почти два десятилетия (1995-2014 гг.) средний возраст матери при рождении первого ребенка увеличился на 2,7 года. По сравнению с другими странами центральной и восточной Европы, в которых трансформация рождаемости также началась в 90-е годы XX века, в Республике Молдова увеличение среднего возраста матери при рождении первого ребенка происходит более низкими темпами. Так, за этот же период в России, Эстонии, Латвии, Польше значение этого показателя увеличилась более, чем на 3 года, а в Чехии более, чем на 4 года [HFD 2018]. Кроме того, в 2015 г. в Республике Молдова наблюдается снижение этого показателя на 0,3 года, что, на наш взгляд, скорее определяется структурными флуктуациями рождений по типам поселений (город/село), чем какими-либо существенными изменениями общих тенденций в динамике рождаемости.

Таблица 2. Средний возраст матери при рождении ребенка по очередности рождений и стандартное отклонение среднего возраста, 1991-2015, лет

\begin{tabular}{c|c|c|c|c|c|c|c|c}
\hline \multirow{2}{*}{ Годы } & \multicolumn{2}{c}{ Средний возраст матери при рождении и по очередности рождений } & \multicolumn{4}{c}{ Стандартное отклонение } \\
\cline { 2 - 9 } & Все рождения & Первые & Вторые & Tретьи & sdt & sd1 & sd2 & sd3 \\
\hline 1991 & 25,1 & 22,3 & 25,8 & 29,4 & 5,3 & 3,9 & 4,2 & 4,6 \\
1992 & 25,0 & 22,2 & 25,7 & 29,1 & 5,2 & 3,8 & 4,2 & 4,5 \\
1993 & 24,9 & 22,1 & 25,7 & 29,1 & 5,3 & 3,9 & 4,2 & 4,6 \\
1994 & 24,8 & 22,0 & 25,8 & 29,2 & 5,2 & 3,8 & 4,2 & 4,5 \\
1995 & 24,7 & 21,9 & 25,7 & 29,0 & 5,2 & 3,9 & 4,3 & 4,5 \\
1996 & 24,8 & 22,1 & 25,9 & 29,1 & 5,3 & 4,0 & 4,3 & 4,6 \\
1997 & 25,0 & 22,3 & 25,8 & 29,1 & 5,3 & 4,0 & 4,3 & 4,7 \\
1998 & 25,1 & 22,4 & 26,1 & 29,6 & 5,3 & 4,0 & 4,3 & 4,8 \\
1999 & 25,2 & 22,6 & 26,2 & 29,6 & 5,3 & 4,0 & 4,3 & 4,7 \\
2000 & 25,1 & 22,6 & 26,3 & 29,5 & 5,2 & 4,0 & 4,3 & 4,7 \\
2001 & 25,3 & 22,7 & 26,5 & 29,8 & 5,2 & 4,0 & 4,3 & 4,7 \\
2002 & 25,7 & 23,0 & 26,8 & 30,2 & 5,3 & 4,1 & 4,3 & 4,7 \\
2003 & 25,9 & 23,2 & 27,1 & 30,2 & 5,2 & 4,0 & 4,4 & 4,6 \\
2004 & 26,1 & 23,4 & 27,4 & 30,5 & 5,3 & 4,1 & 4,4 & 4,7 \\
2005 & 26,2 & 23,5 & 27,5 & 30,5 & 5,3 & 4,1 & 4,4 & 4,7 \\
2006 & 26,4 & 23,6 & 27,7 & 30,9 & 5,3 & 4,1 & 4,5 & 4,6 \\
2007 & 26,6 & 23,9 & 28,0 & 31,1 & 5,3 & 4,2 & 4,5 & 4,7 \\
2008 & 26,9 & 24,2 & 28,3 & 31,2 & 5,4 & 4,4 & 4,5 & 4,7 \\
2009 & 27,1 & 24,3 & 28,4 & 31,5 & 5,5 & 4,5 & 4,6 & 4,6 \\
2010 & 27,1 & 24,5 & 28,6 & 31,6 & 5,5 & 4,6 & 4,7 & 4,7 \\
2011 & 27,2 & 24,5 & 28,6 & 31,7 & 5,5 & 4,6 & 4,7 & 4,7 \\
2012 & 27,4 & 24,6 & 28,7 & 31,7 & 5,6 & 4,7 & 4,8 & 4,7 \\
2013 & 27,5 & 24,6 & 28,7 & 31,8 & 5,7 & 4,8 & 4,8 & 4,7 \\
2014 & 27,5 & 24,4 & 28,8 & 31,9 & 5,7 & 4,8 & 4,8 & 4,7 \\
2015 & 27,3 & 24,1 & 28,5 & 31,7 & 5,8 & 4,7 & 5,0 & 5,0 \\
\hline
\end{tabular}

Источник: Расчеты автора на основе данных статистики о рождениях и численности наличного населения.

Примечание: С 1998 г. без Приднестровья и Муниципия Бендеры.

Таким образом, в настоящее время в Республике Молдова профиль рождаемости является одним из самых молодых в регионе и сопоставим только с показателями Украины. Величина среднего квадратичного отклонения возраста от среднего значения говорит о большом разбросе возрастных показателей рождаемости, более того, за рассматриваемый период наблюдается его увеличение (таблица 2). Откладывание рождения первого ребенка 
сопровождается откладыванием последующих рождений на более поздний период, при том что низкий возраст матери при рождении первого ребенка является одним из факторов, способствующих откладыванию последующих рождений.

Исследования в области рождаемости показывают, что снижение КСР до низкого и чрезвычайно низкого уровней в различных странах происходило за счет рождений разного порядка, что обусловлено разнообразием социально-культурной среды, экономической ситуацией, типом семейной политики, а также возможностями для совмещения семейных и профессиональных ролей [Zeman et al. 2018].

Таблица 3. Итоговая (суммарная) рождаемость для каждой очередности рождения на одну женщину и вклад рождений различной очередности в формирование КСР для календарных лет, 1991-2015

\begin{tabular}{|c|c|c|c|c|c|c|c|c|c|}
\hline \multirow[t]{2}{*}{ Год } & \multicolumn{4}{|c|}{ Очередность рождений } & \multirow{2}{*}{$\begin{array}{c}\begin{array}{c}\text { Суммарная } \\
\text { рождаемость }\end{array} \\
\text { КСР }\end{array}$} & \multicolumn{4}{|c|}{$\begin{array}{c}\text { Вклад рождений различной очередности } \\
\text { в формирование КСР, \% }\end{array}$} \\
\hline & $1-\mathrm{e}$ & $2-\mathrm{e}$ & 3-и & $4+$ & & $1-\mathrm{e}$ & $2-e$ & 3-и & $4+$ \\
\hline 1991 & 1,08 & 0,73 & 0,29 & 0,16 & 2,26 & 47,8 & 32,3 & 12,6 & 7,2 \\
\hline 1992 & 1,02 & 0,73 & 0,29 & 0,16 & 2,20 & 46,4 & 33,1 & 13,4 & 7,2 \\
\hline 1993 & 1,01 & 0,67 & 0,27 & 0,15 & 2,10 & 48,2 & 32,1 & 12,7 & 7,0 \\
\hline 1994 & 0,96 & 0,64 & 0,25 & 0,14 & 1,98 & 48,3 & 32,4 & 12,5 & 6,8 \\
\hline 1995 & 0,88 & 0,60 & 0,22 & 0,12 & 1,81 & 48,3 & 32,9 & 12,0 & 6,7 \\
\hline 1996 & 0,82 & 0,55 & 0,20 & 0,11 & 1,68 & 48,9 & 32,7 & 11,8 & 6,6 \\
\hline 1997 & 0,86 & 0,60 & 0,22 & 0,12 & 1,80 & 47,8 & 33,4 & 12,0 & 6,7 \\
\hline 1998 & 0,79 & 0,53 & 0,18 & 0,12 & 1,63 & 48,7 & 32,8 & 11,3 & 7,2 \\
\hline 1999 & 0,77 & 0,50 & 0,17 & 0,10 & 1,54 & 50,3 & 32,4 & 11,1 & 6,2 \\
\hline 2000 & 0,77 & 0,46 & 0,16 & 0,09 & 1,48 & 52,0 & 31,1 & 10,5 & 6,4 \\
\hline 2001 & 0,74 & 0,47 & 0,15 & 0,09 & 1,46 & 50,9 & 32,2 & 10,6 & 6,3 \\
\hline 2002 & 0,71 & 0,49 & 0,15 & 0,09 & 1,44 & 49,3 & 33,9 & 10,5 & 6,4 \\
\hline 2003 & 0,72 & 0,50 & 0,16 & 0,09 & 1,46 & 49,0 & 33,9 & 11,2 & 5,9 \\
\hline 2004 & 0,75 & 0,52 & 0,17 & 0,08 & 1,53 & 49,5 & 34,0 & 10,9 & 5,6 \\
\hline 2005 & 0,74 & 0,52 & 0,17 & 0,09 & 1,51 & 48,9 & 34,3 & 11,1 & 5,8 \\
\hline 2006 & 0,74 & 0,53 & 0,16 & 0,08 & 1,52 & 48,5 & 35,2 & 10,8 & 5,6 \\
\hline 2007 & 0,75 & 0,55 & 0,17 & 0,08 & 1,56 & 48,4 & 35,3 & 11,1 & 5,2 \\
\hline 2008 & 0,80 & 0,57 & 0,18 & 0,08 & 1,62 & 49,0 & 35,1 & 10,9 & 5,0 \\
\hline 2009 & 0,83 & 0,60 & 0,19 & 0,09 & 1,71 & 48,7 & 34,8 & 11,3 & 5,2 \\
\hline 2010 & 0,85 & 0,57 & 0,19 & 0,08 & 1,69 & 50,3 & 33,8 & 11,1 & 4,9 \\
\hline 2011 & 0,80 & 0,56 & 0,19 & 0,08 & 1,63 & 49,2 & 34,3 & 11,4 & 5,1 \\
\hline 2012 & 0,78 & 0,60 & 0,19 & 0,08 & 1,65 & 47,3 & 36,1 & 11,5 & 5,1 \\
\hline 2013 & 0,75 & 0,57 & 0,20 & 0,08 & 1,59 & 46,9 & 35,6 & 12,3 & 5,2 \\
\hline 2014 & 0,74 & 0,60 & 0,22 & 0,09 & 1,65 & 45,1 & 36,1 & 13,2 & 5,5 \\
\hline 2015 & 0,72 & 0,59 & 0,21 & 0,09 & 1,61 & 44,6 & 36,3 & 13,3 & 5,7 \\
\hline
\end{tabular}

Источник: Расчеты автора на основе данных статистики о рождениях и численности наличного населения.

Примечание: С 1998 г. без Приднестровья и Муниџипия Бендеры.

С начала 90-х годов вплоть до 2002 г. снижение рождаемости в Республике Молдова происходило за счет снижения интенсивности рождений всех порядков, но наибольшее сокращение наблюдается для третьих, четвертых и более высокого ранга рождений (таблица 3). Изменился и вклад рождений различной очерёдности в формирование КСР: несколько повысился вклад рождений первой очередности, вклад вторых рождений существенно не изменился, тогда как вклад рождений третьего и более высокого порядков сократился. 
С 2002 г., когда началось постепенное повышение КСР, структура рождаемости по очередности менялась достаточно динамично. Показатели суммарной рождаемости увеличивались для первых, вторых и третьих порядков, но для четвертых и более высоких рангов стагнировали примерно на одном уровне. В 2008-2011 гг. были достигнуты самые высокие значения суммарной рождаемости для рождений первой очередности $(0,8-0,85$ рождений на одну женщину), однако они существенно ниже, чем в начале 90-х годов. Суммарная рождаемость по очередности рождений, как и КСР, повышалась до 2009 г., затем опять началось снижение показателей, имеющее достаточно неравномерный характер. Так, суммарная рождаемость для первых рождений снизилась до уровня начала 2000-х годов, для вторых рождений с некоторыми колебаниями сохраняется примерно на одном уровне, однако для третьих рождений значения увеличились до уровня середины 90-х годов. Соответственно повысился вклад вторых и третьих рождений в формирование общей суммарной рождаемости. Суммарная рождаемость для четвертых и более высоких порядков сохраняется примерно на одном уровне, несущественные колебания наблюдаются и в показателе их вклада в КСР.

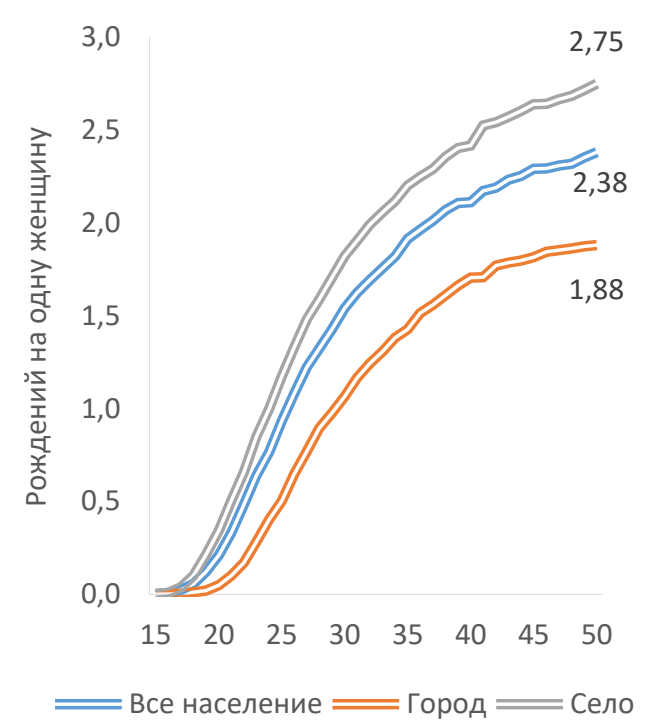

Рисунок 3. Среднее число рождений к определенному возрасту, 2004

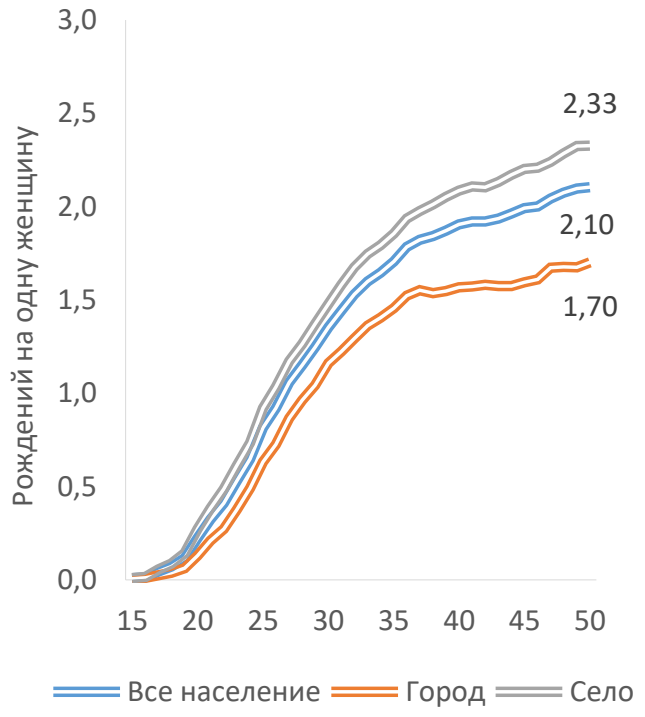

Рисунок 4. Среднее число рождений к определенному возрасту, 2014

Источник: Рассчитано по данным переписей 2004 г. и 2014 г.

Примечание: без Приднестровья и Мунищипия Бендеры.

Сравнение данных о среднем числе рожденных детей к определенному возрасту женщин, показывает, что за период между переписями 2004 и 2014 гг. произошло существенное сокращение рождаемости (рисунки 3 и 4). Для населения в целом этот показатель упал с 2,38 рождения до $2,1(-0,28)$ на одну женщину в возрасте 50 лет при том, что для сельского населения снижение было более существенным (с 2,75 рождения до 2,33; $-0,42$ ) и несколько меньше для городского (с 1,88 рождения до 1,$7 ;-0,18)$. Вместе с тем среднее число детей в расчете на одну женщину в возрасте 50 лет сохраняется на относительно высоком уровне - 2,1 рождения. 
Снижение показателей за период между переписями населения отмечается для всех возрастных групп, которые относятся к основному репродуктивному контингенту (таблица 4.). Для женщин, достигших 30-, 35- и 40-летнего возраста снижение составляет примерно 0,2 рождения на одну женщину, а для 45 -летних - около 0,3 рождения.

Таблица 4. Распределение женщин по числу рожденных детей к определенному возрасту по данным переписей 2004 и 2014 гг.

\begin{tabular}{c|c|c|c|c|c|c}
\hline \multirow{2}{*}{ Возраст } & \multicolumn{2}{|c|}{$\begin{array}{c}\text { Среднее число } \\
\text { рожденных детей }\end{array}$} & $\begin{array}{c}\text { Доля женщин, родивших 3 } \\
\text { и более детей, \% }\end{array}$ & \multicolumn{2}{c}{$\begin{array}{c}\text { Не родили ни одного } \\
\text { ребенка, \% }\end{array}$} \\
\cline { 2 - 7 } & 2004 & 2014 & 2004 & 2014 & 2004 & 2014 \\
\hline 20 & 0,2 & 0,2 & - & - & 81,5 & 81,0 \\
25 & 0,9 & 0,8 & 3,4 & 4,0 & 34,9 & 43,0 \\
30 & 1,5 & 1,3 & 12,1 & 9,6 & 14,0 & 22,0 \\
35 & 1,9 & 1,7 & 21,0 & 17,0 & 8,0 & 14,0 \\
40 & 2,1 & 1,9 & 28,0 & 22,0 & 6,0 & 9,2 \\
45 & 2,3 & 1,9 & 34,0 & 24,0 & 5,4 & 7,0 \\
50 & 2,4 & 2,1 & 35,5 & 28,0 & 5,9 & 6,3 \\
\hline
\end{tabular}

Источник: Рассчитано по данным переписей 2004 и 2014 г.

Примечание: Без Приднестровья и Мунищипия Бендеры.

Следует отметить снижение доли женщин, родивших трех и более детей. Среди женщин, достигших 45 лет, их доля составила 24\%, что на 10 п.п. меньше, чем в 2004 г., также сократилась их доля и среди 50-летних: с 35,5\% до 28,0\%. Несмотря на это, доля женщин, родивших трех и более детей, сохраняется на достаточно высоком уровне, даже к 30 годам почти каждая десятая женщина является многодетной матерью², а к 40 годам каждая пятая.

Добровольная бездетность нехарактерна для Республики Молдова. Социологические опросы показывают высокую значимость деторождения и материнской функции в системе ценностей населения. Рождение как минимум одного ребенка является важной социальной нормой, поэтому доля женщин, не родивших ни одного ребенка к концу репродуктивного возраста (к 50 годам), сохраняется на низком уровне, несмотря на некоторое повышение этого показателя (5,9\% в 2004 г. и 6,3\% в 2014 г.).

Распределение женщин по числу рожденных детей показывает (рисунок 5), что наибольшая доля приходится на женщин, родивших двоих детей, что подтверждает приверженность населения двухдетной модели семьи. Более $45 \%$ женщин в возрасте 40 лет и старше родили двоих детей, достаточно высока их доля и в возрастной группе 30-34летних (39\%) и даже в возрастной группе 25-29 лет почти каждая четвертая женщина уже родила двоих детей.

\footnotetext{
${ }^{2}$ Согласно Закону РМ о социальной помощи №547 от 25.12.2003: «Многодетная семья — семья с тремя и более детьми».
} 


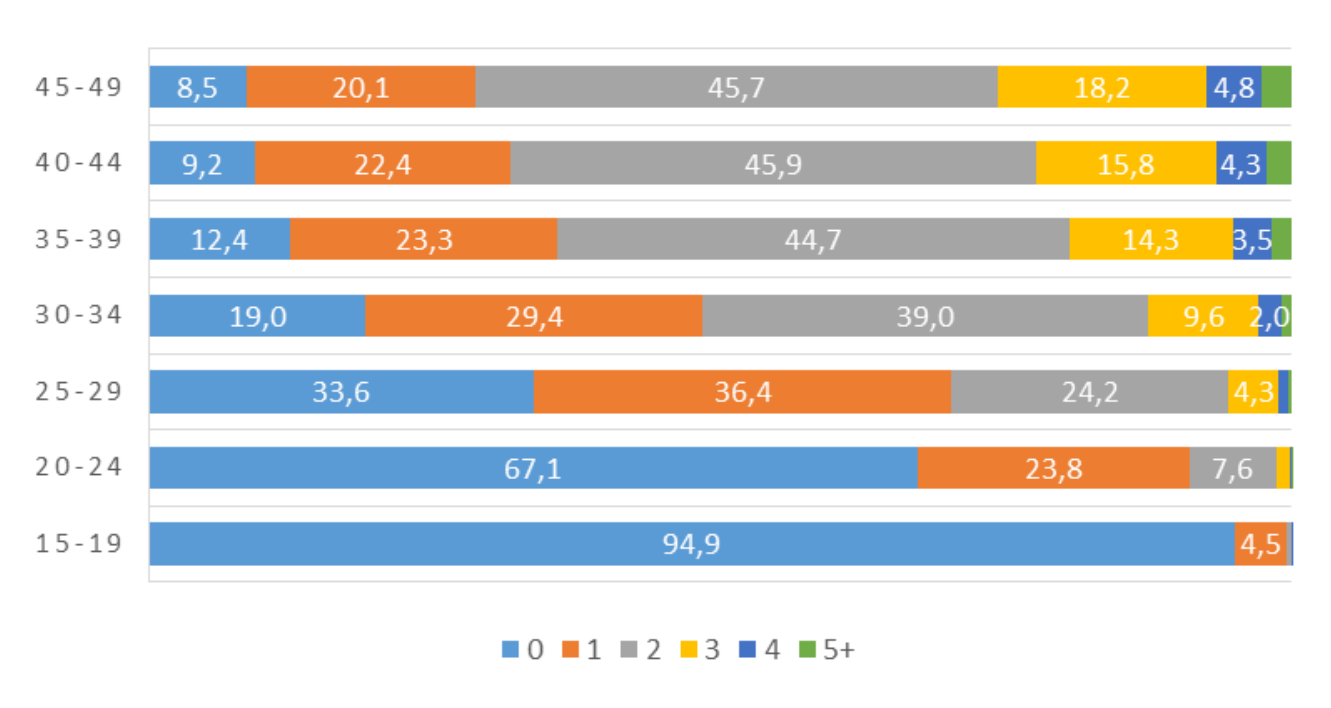

Рисунок 5. Распределение женщин по числу рожденных детей, 2014, \%

Источник: Рассчитано по данным ПНЖ 2014 г.

Примечание: Без Приднестровья и Муниципия Бендеры.

\section{РОЖДАЕМОСТЬ РЕАЛЬНЫХ ПОКОЛЕНИЙ}

Исследования показывают, что рождаемость изменяется относительно медленно и не подвержена большим колебаниям от одного поколения к другому, несмотря на влияние экономических, социальных факторов и различных мер семейной политики. При перестройке календаря рождений итоговая рождаемость реальных поколений может оставаться на прежнем уровне либо может продолжать снижаться. Совокупные эффекты отсрочки деторождения при завершенной рождаемости также остаются относительно незначительными - отчасти потому, что большинство женщин достигают своей первой беременности в возрасте задолго до начала периода возможного бесплодия и таким образом могут реализовать свои репродуктивные установки, но и отчасти потому, что другие факторы могут компенсировать эффекты позднего материнства. Например, во Франции, которая имеет один из самых высоких возрастов при первом материнстве в Европе, сохраняется относительно стабильный уровень итоговой рождаемости поколений, близкий к уровню замещения поколений [Frejka, Sobotka 2008]. В других странах западной и северной Европы переход к модели позднего материнства также не оказал существенного влияния на показатель итоговой рождаемости, тогда как в немецкоязычных странах рождаемость установилась на очень низком уровне. Вместе с тем сокращение рождаемости реальных поколений является ведущей тенденцией для большинства европейских стран, оно происходило в несколько этапов и было обусловлено снижением рождаемости различных порядков [Zeman et al. 2018].

Что касается классификации уровня рождаемости для реальных поколений в терминах «низкой» или «чрезвычайно низкой» рождаемости, то в демографической литературе еще нет общепринятого определения. Как известно, изменения «темпо» приводят к значительному искажению рождаемости для календарных лет и, как правило, 
на протяжении нескольких десятилетий когортные показатели в странах с низкой рождаемостью значительно выше, чем для условных поколений. В недавних исследованиях рождаемость реальных поколений на уровне 1,75 рождения на одну женщину была использована в качестве порога, ниже которого когортная рождаемость может считаться «очень низкой» [Myrskylä, Goldstein, Cheng 2013; Rindfuss, Choe, Brauner-Otto 2016]. Этот же уровень был использован для изучения изменений когортной рождаемости по паритету в странах с низким уровнем рождаемости [Zeman et al. 2018]. В данном исследовании автор также использует порог в 1,75 рождения на одну женщину как показатель низкой рождаемости когорт, при котором замещение поколений обеспечивается только на $85 \%$.

В Республике Молдова наблюдается устойчивая тенденция снижения рождаемости для реальных когорт женщин (рисунок 6). Так, если итоговая рождаемость поколений 30-х годов прошлого столетия была на уровне 2,5 рождения и выше, то $40-x$ и $50-x-$ уже в среднем на уровне 2,2, а 60-х - на уровне, необходимом для воспроизводства поколения или близком к нему. Поколения 70-х, особенно родившиеся в их второй половине и еще не завершившие репродуктивный период, исходя из накопленной рождаемости и прогнозам, в среднем будут иметь еще более низкую рождаемость. Достаточно существенные колебания рождаемости для условных поколений мало отражаются на динамике показателя для реальных поколений, а КСР для календарных лет по-прежнему остается на более низком уровне, чем итоговая рождаемость реальных поколений, которая, несмотря на снижение, сохраняется на относительно высоком уровне, близком к уровню воспроизводства поколений.

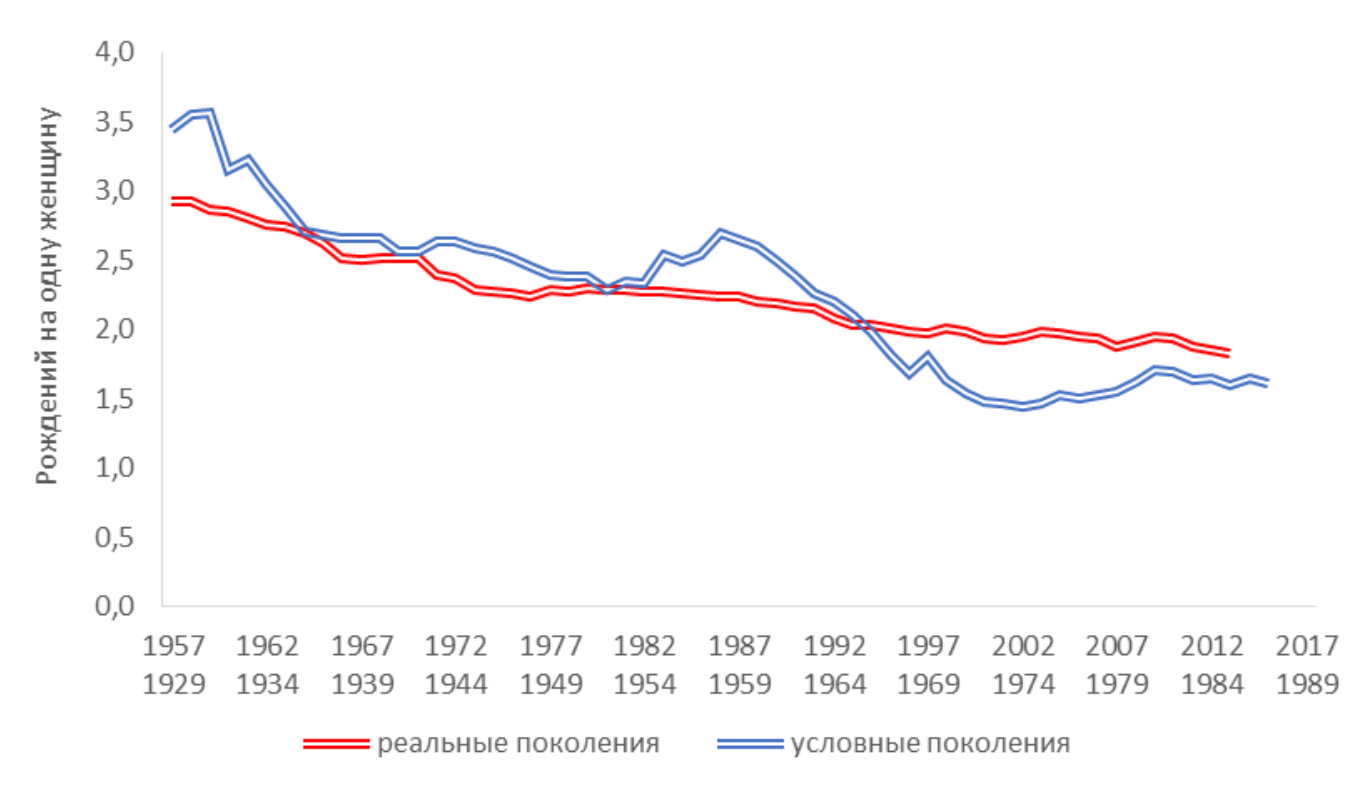

\section{Рисунок 6. Рождаемость условных (1957-2015 гг.) и реальных поколений (1929-1985 годов рождения)}

Источник: Переписи населения, расчеты автора на основе данных текущзей статистики.

Примечание: Для поколений 1971-1985 годов рождения итоговая рождаемость включает и прогноз ожидаемой рождаемости до конца репродуктивного периода. 
Анализ возрастного профиля рождаемости реальных поколений является отражением тенденций, наблюдаемых для условных поколений: существенное сокращение коэффициентов рождаемости в молодых возрастах и постепенное их повышение в возрасте 30 лет и старше (рисунок 7). Выделяются островершинностью и концентрацией рождений в возрасте 20-21 год кривые рождаемости женских когорт 1969-1971 годов рождения, которые в наибольшей степени отреагировали на меры семейной политики социалистического государства 80-х годов. Для более молодого поколения 1975 года рождения кривые рождаемости приобретают более плавную форму, тем не менее наибольшие значения возрастных коэффициентов приходятся на молодой возраст 19-22 года.

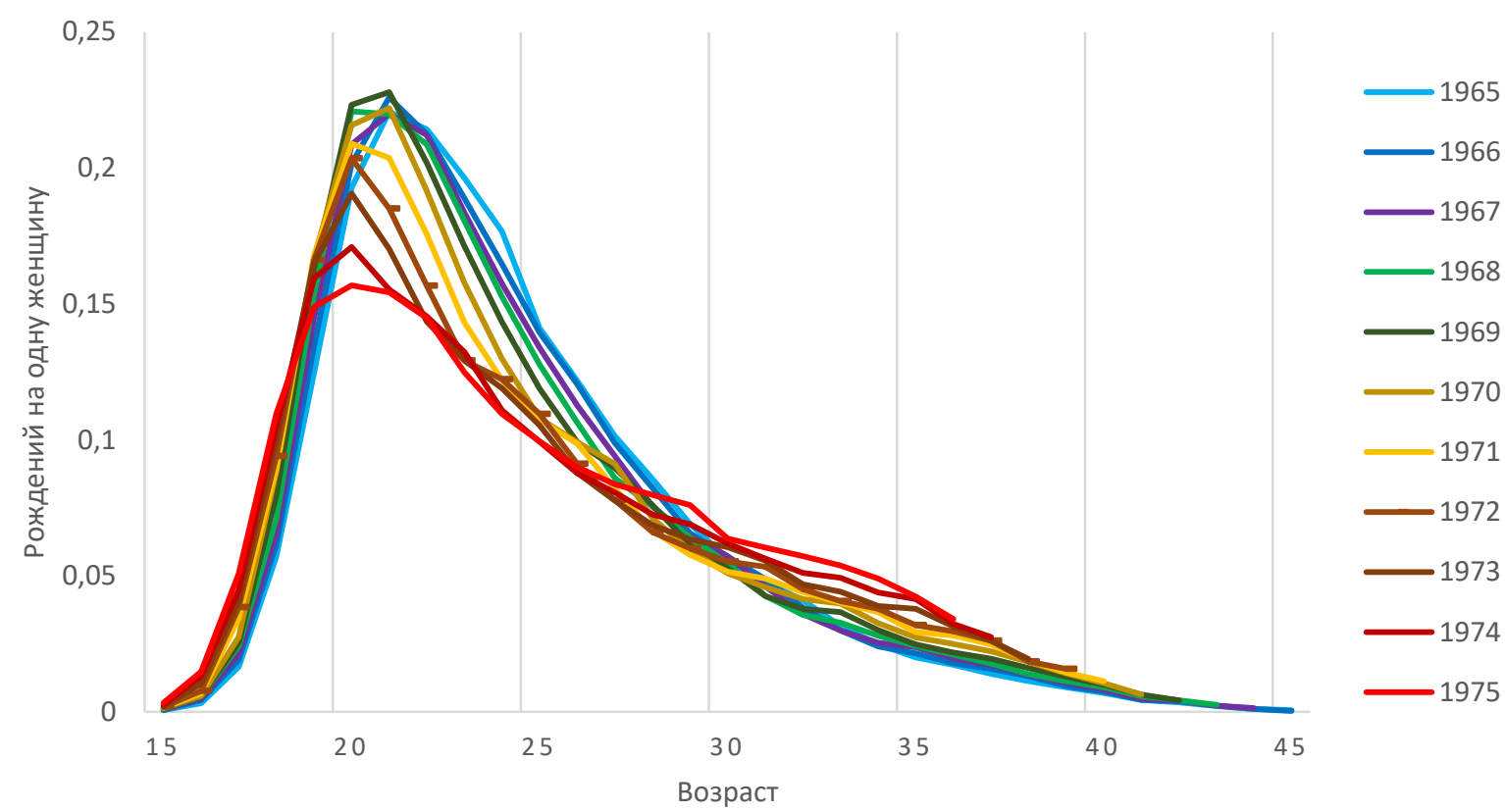

Рисунок 7. Возрастные коэффициенты рождаемости женских поколений 1965-1975 годов рождения

Источник: Расчеты автора на основе данных текущей статистики о рождаемости и данных о населении de facto.

Согласно данным ПНЖ 2014, итоговая рождаемость женских поколений, завершивших или находящихся в возрасте завершения детородного периода - 1965-1968 годов рождения, составляет 2,04-1,99 рождения на одну женщину (таблица 5). Учитывая ранний возраст деторождения, их наиболее высокая репродуктивная активность пришлась на середину-конец 1980-х годов, в период социалистического строя, в таких социальных и экономических условиях, которые поддерживали рождаемость на уровне замещения поколений или близком к нему.

На более молодые поколения (1969-1971 годов рождения), которые на момент ПНЖ 2014 были в возрасте 41-44 года, в среднем приходится 1,97-1,95 рождения. Возраст активного деторождения этих поколений совпал с введением мер семейной политики 80-х годов XX века, которые, как показывает итоговая рождаемость этих поколений, не оказали существенного влияния на итоговую рождаемость этих поколений, а лишь привели к изменению календаря материнства - рождению детей в более раннем возрасте. Можно 
предположить, что их итоговая рождаемость несколько увеличится, но незначительно, так как возрастные коэффициенты рождаемости в возрасте 45 лет и старше приближаются к нулю.

Женские поколения, родившиеся в середине 70-х годов прошлого столетия и достигшие на момент ПНЖ 2014 возраста 37-40 лет, перешагнули рубеж 1,8 рождений на одну женщину, а самое молодое поколение женщин 1980 года рождения к 33-34-летнему возрасту на момент переписи достигло уровня 1,6 рождений на одну женщину.

Таблица 5. Рождаемость реальных поколений женщин 1965-1980 годов рождения

\begin{tabular}{l|c|c|c|c|c}
\hline $\begin{array}{l}\text { Возраст } \\
\text { в 2014 г., }\end{array}$ & $\begin{array}{c}\text { Год } \\
\text { рождения } \\
\text { когорты }\end{array}$ & $\begin{array}{c}\text { Оценки на основе } \\
\text { преобразования } \\
\text { данных текущей } \\
\text { статистики }\end{array}$ & $\begin{array}{c}\text { Среднее число } \\
\text { рожденных детей } \\
\text { по данным ПНЖ } \\
2014 \text { г. }\end{array}$ & $\begin{array}{c}\text { Разница между } \\
\text { оценками и } \\
\text { ПНЖ 2014 г. }\end{array}$ & $\begin{array}{c}\text { Прогнозируемая } \\
\text { итоговая } \\
\text { рождаемость }\end{array}$ \\
\hline $48-49$ & 1965 & 2,00 & 2,04 & $-0,04$ & - \\
$47-48$ & 1966 & 2,03 & 2,04 & $-0,01$ & - \\
$46-47$ & 1967 & 2,00 & 2,00 & 0,00 & - \\
$45-46$ & 1968 & 2,00 & 1,99 & 0,01 & 2,01 \\
$44-45$ & 1969 & 2,01 & 1,97 & 0,04 & 1,98 \\
$43-44$ & 1970 & 2,01 & 1,94 & 0,07 & 1,94 \\
$42-43$ & 1971 & 1,95 & 1,93 & 0,01 & 1,92 \\
$41-42$ & 1972 & 1,91 & 1,91 & 0,00 & 1,95 \\
$40-41$ & 1973 & 1,86 & 1,91 & $-0,05$ & 1,98 \\
$39-40$ & 1974 & 1,87 & 1,88 & $-0,01$ & 1,98 \\
$38-39$ & 1975 & 1,84 & 1,85 & $-0,01$ & 1,97 \\
$37-38$ & 1976 & 1,89 & 1,82 & 0,07 & 1,95 \\
$36-37$ & 1977 & 1,86 & 1,80 & 0,06 & 1,94 \\
$35-36$ & 1978 & 1,83 & 1,73 & 0,09 & 1,91 \\
$34-35$ & 1979 & 1,78 & 1,67 & 0,10 & 0,10 \\
$33-34$ & 1980 & 1,70 & 1,60 & & - \\
\hline
\end{tabular}

Источник: Данные ПНЖ 2014, расчеты автора на основе данных текущей статистики.

Примечание: Для прогнозирования итоговой рождаемости использовали гамма-функцию.

Следует отметить, что оценки итоговой/накопленной рождаемости, сделанные на основе преобразования данных текущей статистики о рождаемости и использования оценок о численности наличного населения, достаточно хорошо согласуются с результатами ПНЖ 2014. Только для самых молодых поколений 1978-1980 годов рождения разница приближается к 0,1 рождения на одну женщину. Прогноз итоговой рождаемости даже для самых молодых поколений дает оценки не ниже 1,9 рождения на одну женщину, что свидетельствует о сохранении в Республике Молдова относительно высокого уровня рождаемости.

Наибольшую долю в когортах 1965-1970 годов рождения, завершивших или приближающихся к завершению репродуктивного периода, составляют женщины, родившие двоих детей (45-47\%). В когортах 1967-1970 годов рождения наблюдается увеличение доли женщин, родивших только одного ребенка (до 22,9\%), и сокращение рождений третьего и более высокого порядка. Так, если среди женщин, родившихся в 1965 г., доля тех, кто родил троих и более детей составила 26,9\%, то среди женщин 1970 года рождения несколько меньше - 22,9\% (рисунок 8). 
Доля женщин, которые не родили ни одного ребенка, невысока и составляет 6,6-7,1\% для женских поколений 1965-1968 годов рождения и 8-8,6\% для более молодых поколений 1969-1970 годов рождения.

Более молодые поколения (1971-1975 годов рождения), еще не завершившие репродуктивный период, вероятно, укрепят установившиеся тенденции. На момент ПНЖ 2014 их возраст чуть превышал или приближался к 40 годам, что позволяет предположить, что еще не реализованные рождения не внесут существенных изменений в их итоговую рождаемость и распределение по числу рожденных детей.

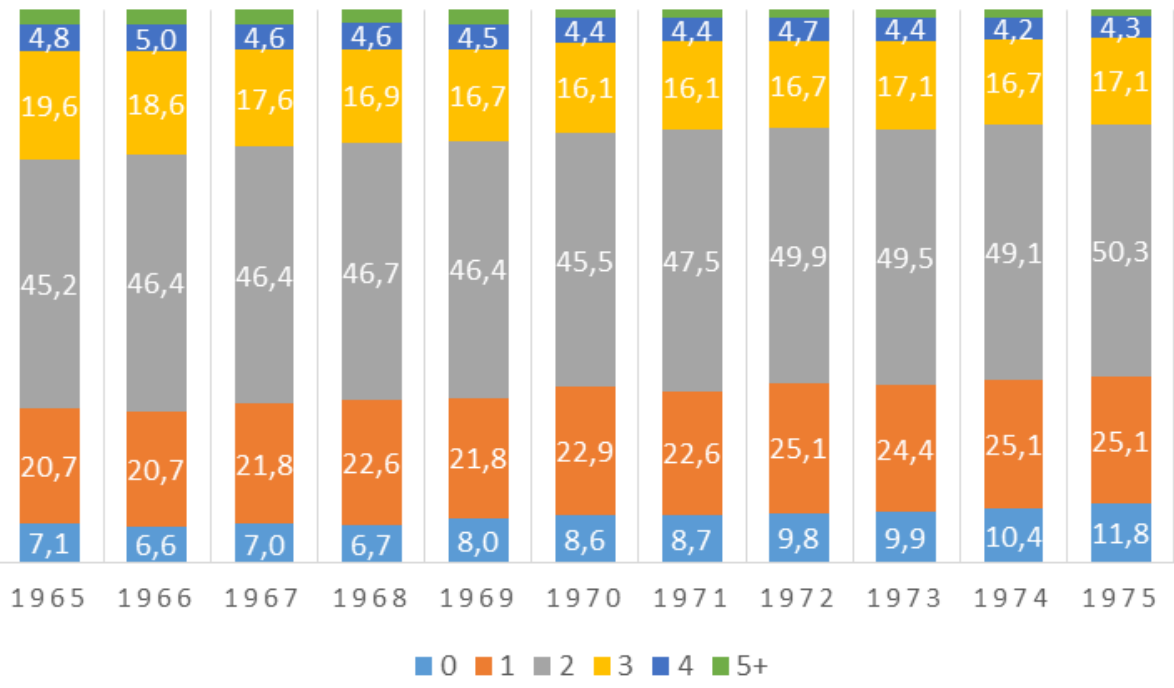

Рисунок 8. Женские поколения 1965-1975 годов рождения по числу рожденных детей, \%

Источник: Данные ПНЖ 2014.

\section{СОЦИАЛЬНО-ЭКОНОМИЧЕСКИЙ И КУЛЬТУРНЫЙ КОНТЕКСТЫ РЕСПУБЛИКИ МОЛДОВА И ИХ ВЛИЯНИЕ НА РОЖДАЕМОСТЬ}

После обретения независимости в 1991 г. Республика Молдова столкнулась с затяжным социально-экономическим кризисом, снижением уровня жизни широких слоев населения, распространением бедности. Несмотря на некоторое улучшение ситуации в определённые периоды, напряжённость сохраняется по настоящее время, реализовать существенный экономический прорыв и улучшить материальные условия жизни населения стране не удалось, что является одним из выталкивающих факторов для молодого образованного населения в поисках работы или переезда в страны с более высоким уровнем жизни.

Вместе с тем социальные трансформации, рост территориальной мобильности населения способствовали культурной и нормативной либерализации, вызвавшей быстрое изменение взглядов молодежи на супружество, семью и место ребенка в иерархии приоритетов и решений, а также моделей семьи, сексуального и матримониального поведения. 
Массовая миграция, особенно из сельской местности, разделила многие семьи, а длительное раздельное проживание во многих случаях привело к распаду брака. Эти тенденции были наиболее характерны для конца 1990-х - начала 2000-х годов. Изменение миграционной политики принимающих стран и либерализация визового режима со странами ЕС, с одной стороны, помогли многим семьям воссоединиться, а с другой способствовали повышению интенсивности миграции, в том числе семейной.

Широкое вовлечение женщин в трудовую миграцию оказало влияние на изменение их репродуктивных установок. В настоящее время нет исследований, позволяющих измерить влияние трудовой миграции на рождаемость, тем не менее доступные данные говорят о снижении репродуктивных намерений женщин-трудовых мигрантов, которые ввиду сложности материальной ситуации и необходимости работать вынуждены пересматривать свои планы, откладывая рождение ребенка или отказываясь от него [Женщины-мигранты... 2011].

Одним из факторов, влияющих на рождаемость в Республике Молдова, является распределение населения между городскими и сельскими поселениями. Так, продолжает сохраняться низкий уровень урбанизации (38\% от общего населения страны), более того, за годы независимости доля сельских жителей в общей численности населения увеличилась, что обусловлено территориальным разделением правого и левого берегов Днестра и ведением статистики без Приднестровья с относительно высокой долей городского населения. Низкая доступность жилья, отсутствие рабочих мест, особенно в небольших городах, привели к снижению внутренней миграции из села в город, что, в свою очередь, привело к увеличению численности и доли экономически неактивного населения в сельской местности.

Большая экономическая, социальная, культурная и демографическая разница между городским и сельским населением определяет специфику воспроизводства населения страны. Рождаемость сельского населения оказывает определяющее влияние на уровень и характеристики рождаемости страны в целом в силу того, что на протяжении последних двух десятилетий доля рождений в сельской местности в общей численности рождений составляет около $62-65 \%$.

Низкий уровень занятости, особенно в сельской местности, определяет высокую долю незастрахованных получателей пособий при рождении и по уходу за ребенком и оказывает негативное влияние на материальное положение семей после рождения ребенка. Из общего числа получателей разовых пособий по рождению ребенка в 2004-2015 гг. более $2 / 3$ составляют незастрахованные лица, а среди получателей ежемесячных пособий - более 1/2. Размер пособий не покрывает размер прожиточного минимума на ребенка, соотношение размеров ежемесячного пособия и прожиточного минимума для застрахованных лиц составляет около 80\%, а для незастрахованных -только $30 \%$.

Быстрое сокращение населения и неблагоприятные демографические показатели (низкая ожидаемая продолжительность жизни, рождаемость, не обеспечивающая воспроизводство населения, массовая эмиграция) вызвали необходимость принятия Стратегической национальной программы в области демографической безопасности Республики Молдова на 2011-2025 гг. Одним из ее приоритетов является повышение 
уровня рождаемости путем создания благоприятных условий для совмещения профессиональных и семейных ролей, развития системы услуг для детей, в том числе в возрасте до трех лет (ясли/детские сады), улучшения доступа населения к качественным услугам по планированию семьи.

За мониторинг и координацию процесса внедрения Стратегии отвечает Министерство здравоохранения, труда и социальной защиты, а контроль за выполнением был возложен на Национальную комиссию по народонаселению и развитию при правительстве Республики Молдова. В 2016 г. независимые эксперты провели оценку внедрения плана работы на 2011-2016 гг. [Buzu, Lutenco 2016]. Основные выводы экспертов сводятся к тому, что программа малоэффективна, многие политические инициативы носят общий и декларативный характер, не имеют конкретно установленных целей, во многих случаях относятся к общей сфере деятельности и ответственности министерств, а ее финансовая необеспеченность не позволяет реализовать намеченные цели. Было рекомендовано в новом плане работ сконцентрироваться на специфических проблемах, установить конкретные цели и сроки их реализации, а также процесс мониторинга и координации. Однако новый план до сих пор не был принят, кроме того, Национальная комиссия в области населения и развития перешла в субординацию Министерства здравоохранения, труда и социальной защиты, что значительно ограничивает ее возможности по контролю и межведомственной координации процесса внедрения программы.

Вместе с тем за предшествующий период были достигнуты некоторые положительные изменения в области семейной политики. Так, одним из важных шагов в продвижении участия отцов в семейной жизни и воспитании детей являются принятые в 2016 г. законодательные изменения, согласно которым отец новорожденного ребенка имеет право на отпуск по отцовству продолжительностью 14 календарных дней, предоставляемый по письменному заявлению в течение первых 56 дней после рождения ребенка.

Отпуск по отцовству оплачивается из фонда социального страхования в размере средней заработной платы за соответствующий период, при этом период отчислений в социальный фонд должен составлять не менее трех лет. Работодатель обязан поощрять работников к использованию отпуска по отцовству.

Для поддержания материального уровня семей с детьми и создания благоприятных условий для реинтеграции женщин на рынке труда выплата ежемесячного пособия по уходу/воспитанию ребенка не прекращается, если мать или отец (получатель пособия) восстанавливается на работе на условиях сокращенной продолжительности рабочего времени. Если же получатель выплаты трудоустраивается или восстанавливается на работе на условиях полной продолжительности рабочего времени до истечения отпуска по уходу за ребенком, назначенное ежемесячное пособие по уходу/воспитанию ребенка отменяется.

Кроме того, была сокращена продолжительность отпуска по уходу за ребенком, который еще до недавнего времени составлял 3 года оплачиваемого и еще 3 года неоплачиваемого отпуска с сохранением рабочего места. В 2017 г. были внесены соответствующие изменения в трудовое законодательство, согласно которым отпуск по уходу за ребенком сократился до четырех лет, из них 3 года - оплачиваемый отпуск. 
Следует также отметить некоторые успехи, достигнутые в области планирования семьи и репродуктивного здоровья. В последнее десятилетие особое внимание было уделено сокращению абортов и улучшению услуг по прерыванию беременности. При поддержке ВО3 и других международных организаций были разработаны и утверждены Правила и стандарты для проведения безопасных абортов, созданы 6 центров-моделей по оказанию комплексных услуг по прерыванию беременности в амбулаторных условиях. В результате значительно улучшились показатели структуры методов прерывания беременности, значительно сократилась доля абортов, проводимых с помощью кюретажа (с 45\% до 24\% в 2010-2015 гг.) и увеличилась доля более безопасных методов - вакуумной аспирации (с 54\% до 62\%) и медикаментозного аборта (с 1\% до 14\%).

Несмотря на некоторое сокращение (с 41,2 на 100 живорожденных в 2008 г. до 34,2 в 2015 г.), уровень абортов остается достаточно высоким и по-прежнему остается одним из способов внутрисемейного регулирования рождаемости.

Доля замужних и женщин, находящихся в партнерском союзе, использующих современные методы контрацепции, достаточно низка $(41,7 \%)$, а финансовая недоступность современных методов контрацепции и низкий уровень информированности населения являются основными причинами их низкого распространения. Гормональная оральная контрацепция используется незначительной частью женщин (5\%), большее распространение получили внутриматочное средство (20\%) и презерватив (12\%) [National Centre... 2014].

\section{Выводы}

Несмотря на то, что итоговая рождаемость реальных поколений сохраняется на относительно высоком уровне, близком к замещению поколений, сокращение численности населения в молодых возрастах в результате миграции неизбежно ведет к сокращению числа рождений для календарных лет, что в ближайшей и среднесрочной перспективе будет иметь серьёзные социально-экономические и демографические последствия для страны.

Снижение рождаемости в Республике Молдова является закономерной тенденцией, вызванной вторым демографическим переходом, начавшимся в странах восточной Европы в середине 90-х годов прошлого столетия. По сравнению с другими странами это снижение началось с более высоких уровней, однако уже в начале 2000 -х годов КСР снизился до уровней, сопоставимых с другими постсоветскими странами европейского региона. Вместе с тем исследование уровня рождаемости для условных и реальных поколений показало, что Республика Молдова не относится к странам с низкой или очень низкой рождаемостью (low fertility or lowest-low fertility).

Общий профиль рождаемости сохраняет черты восточно-европейской модели, что прослеживается в распределении возрастных коэффициентов рождаемости, а также среднем возрасте деторождения. Несмотря на структурные изменения, процесс постарения материнства идет медленными темпами, молодой профиль рождаемости по-прежнему сохраняется, более того, рост среднего возраста матери при рождении первого ребенка приостановился. 
Более высокий по сравнению с другими странами уровень рождаемости, а также медленные темпы перестройки рождаемости определяются высокой долей сельского населения в общей структуре, способствующей сохранению традиционного образа жизни, гендерных стереотипов и соответствующей модели рождаемости.

\section{ЛИТЕРАТУРА}

Архангельский В.Н. (2018). Рождаемость // Демографическое развитие постсоветского пространства: сб. статей и аналитических материалов / Под. ред. М.Б. Денисенко, Р.В. Дмитриева, В.В. Елизарова. М.: Экономический факультет МГУ им. М.В. Ломоносова. 55 c. URL: https://www.econ.msu.ru/sys/raw.php?o=44887\&p=attachment (дата обращения: 21.02.2018).

Гагауз О. (2011). Низкая рождаемость в Молдове // Демоскоп Weekly. 457-458. URL: http://demoscope.ru/weekly/2011/0457/tema01.php (дата обращения: 10.01.2018).

Гагауз О. (2012). Молдова в процессе глобализации низкой рождаемости // Демографическое развитие: вызовы глобализации. Седьмые Валентеевские чтения. Международная конференция (Москва, Россия, 15-17 ноября 2012 г.) / Под ред. В.А. Ионцева и др. М.: МАКС Пресс: 261-270.

Гагауз О. (2013). Молдова на пути второго демографического перехода: структурные изменения рождаемости // Экономический рост в условиях глобализации. Вып.8. Материалы международной научно-практической конференции, научная сессия "Демографическое развитие: вызовы для социальной политики" (Кишинев, 17-18 окт. 2013): 36-46.

Женщины-мигранты из стран СНГ в России (2011) / Под ред. Е.В. Тюрюканова. М.: МАКС Пресс. 120 с.

Фрейка Т., С. Захаров (2014). Эволюция рождаемости в России за полвека: оптика условных и реальных поколений // Демографическое обозрение. 1: 106-143.

Щербакова Е.М. (2016). Демографическая ситуация в странах СНГ, 2014 год // Демоскоп Weekly. 675-676. URL: http://demoscope.ru/weekly/2016/0675/barom01.php (дата обращения: 10.01.2018).

Billingsley S. (2010). The post-communist fertility puzzle // Population Research and Policy Review. 29(2): 193-231.

Buzu A., V. Lutenco (2016). Are we up to the task? Assessment report of the National Strategic Programme on Demographic security 2011-2025. Chisinau: 95.

Fokkema T., A. Liefbroer (2008). Trends in living arrangements in Europe: Convergence or divergence? // Demographic Research. 19 (36): 1351-1418.

Frejka T. (2008). Overview Chapter 5: Determinants of family formation and childbearing during the societal transition in Central and Eastern Europe. Demographic research volume. 9(7): 139-170. URL: http://www.demographic-research.org/Volumes/Vol19/7/ DOI: 10.4054/DemRes.2008.19.7 (accessed: 22.01.2018).

Frejka T. (2012). The role of contemporary childbearing postponement and recuperation in shaping period fertility trends // Comparative Population Studies. 36(4): 927-957. 
Frejka T., T. Sobotka (2008). Overview Chapter 1: Fertility in Europe: Diverse, delayed and below replacement // Demographic research. 19(3):15-46. URL: http://www.demographicresearch.org/Volumes/Vol19/3/ DOI: 10.4054/DemRes.2008.19.3. (accessed: 20.12.2017).

Gagauz O. (2016). Low fertility rate and population decline // Population Situation Analysis in the Republic of Moldova / Gagauz Olga, Stratan A. et al., eds. Chisinau: 63-69. URL: http://ccd.md/en/20-principala-mod/143-population-situation-analysis-in-the-republic-ofmoldova (accessed: 21.12.2017).

HFD (2018). The Human Fertility Database. Max Planck Institute for Demographic Research (Germany) and Vienna Institute of Demography (Austria). URL: www.humanfertility.org (data downloaded on 22.04.2018).

Kohler H.-P., F. Billari, J. Ortega (2002). The emergence of lowest-low fertility in Europe during the 1990s. // Population and Development Review. 28(4): 641-681.

Kuijsten A. (1996). Changing family patterns in Europe: a case of divergence // European Journal of Population. 12(2): 115-143.

McDonald P. (2008). Very low fertility consequences, causes and policy approaches // The Japanese Journal of Population. 6(1). URL: http://www.ipss.go.jp/webjad/WebJournal.files/Population/2008_4/02mcdonald.pdf (accessed: 10.12.2017).

Myrskylä M., J. Goldstein, Y.-H.A. Cheng (2013). New cohort fertility forecasts for the developed world: rises, falls, and reversals // Population and Development Review. 39(1): $31-56$

National Centre of Public Health of the Ministry of Health of the Republic of Moldova, United Nations Children's Fund (UNICEF) (2014). 2012 Republic of Moldova Multiple Indicator Cluster Survey MICS, Final Report. Chisinau, Republic of Moldova.

Penina O., D.A. Jdanov, P. Grigoriev (2015). Producing reliable mortality estimates in the context of distorted population statistics: the case of Moldova // MPIDR Working Paper WP2015-011, 35 pages (November 2015). Rostock: Max Planck Institute for Demographic Research.

Perelli-Harris B. (2008). Ukraine: on the border between old and new. Childbearing trends and policies: Country case studies / T. Frejka, J. Hoem, L. Toulemon, eds. Demographic Research. 19:29. 1145-1178.

Rindfuss R.R., M.K. Choe, S.R. Brauner-Otto (2016). The emergence of two distinct fertility regimes in economically advanced countries // Population Research and Policy Review. 35(3): $287-304$.

Sobotka T. (2011). Fertility in Central and Eastern Europe after 1989: collapse and gradual recovery // Historical Social Research. 36. 2: 246-296.

Sobotka T. (2003). Re-emerging diversity: rapid fertility changes in Central and Eastern Europe after the collapse of the communist regimes // Population Journal. 58(4/5):451-485.

Sobotka T. (2008). The diverse faces of the second demographic transition in Europe // Demographic Research. 19(8): 171-224.

Sobotka T. (2017). Post-transitional fertility: childbearing postponement and the shift to low and unstable fertility levels // Vienna Institute of Demography Working Paper and Human Fertility Database Research Report VID WP 01/2017 and HFD RR 01/2017: 37. 
Zakharov S. (2008). Russian Federation: From the first to the second demographic transition / T. Frejka, J.M. Hoem, T. Sobotka, L. Toulemon, eds. // Childbearing Trends and Policies in Europe. Max Planck Institute for Demographic Research: 907-972.

Zeman K., E. Beaujouan, Z. Brzozowska,T. Sobotka (2018). Cohort fertility decline in low fertility countries: Decomposition using parity progression ratios // Demographic research. 38(25): 651-690. 


\title{
FERTILITY IN THE REPUBLIC OF MOLDOVA: EUROPEAN TRENDS AND NATIONAL PARTICULARITIES
}

\section{OLGA GAGAUZ}

\begin{abstract}
Currently, the official statistics of the Republic of Moldova, based on de jure population data that include citizens who are absent 12 months or more from the country, give underestimated total fertility rates, which has led to the country's being classified as among those with lowest-low fertility.

Based on de facto population data and the results of the Population and Housing Census of 2014, the level and main trends in fertility dynamics are analyzed from a period and cohort perspective. The main goal of the study is to trace to what level the fertility rate has decreased in the Republic of Moldova and whether it can be considered a country with low or lowest-low fertility.
\end{abstract}

The results of the research show that the transformation of fertility is taking place according to the general model specific to most countries that have completed or are in the process of fertility transition, but is characterized by a slower pace. In the last few years, the period fertility rate has become fixed at 1.6-1.65 births per woman, whereas for cohorts that have completed or are at the end of the reproductive period it is 1.9-2.0 births per woman. Even for the youngest generations, who had reached the age of 35 at the time of the census (2014), the average number of children born exceeded 1.7. Although the average number of births was decreasing by the end of the reproductive period in the intercensal period, the average number of births per women at the age of 50 was 2.1, and the proportion of those who have not given birth to any child remains relatively low.

\begin{abstract}
Based on the results of the study, the author concludes that the Republic of Moldova does not belong to the group of countries with low or lowest-low fertility, and that the preservation of a higher fertility than in other countries is determined by the predominance of the rural population in the general structure.
\end{abstract}

Key words: fertility, period and cohort indicators, age-specific fertility rates, mother's mean age at birth, cumulative fertility.

Olga Gagauz (gagauzo@inbox.ru), National Institute for Economic Research, RePublic of Moldova.

DATE RECEIVED : JUNE 2018.

\section{REFERENCES}

Arhangeliskiy V.N. (2018). Rozhdaemost' [Natality] // Demograficheskoe razvitie postsovetskogo prostranstva: sb. statey i analiticheskikh materialov [Demographic development of the post-Soviet space: collection of articles and analytical materials] / M.B. Denisenko, R.V. Dmitreeva, V.V. Ylizarova, eds. Moscow: Ekonomicheskiy fakul'tet MGU im. M.V. Lomonosova. 55 p. URL:

https://www.econ.msu.ru/sys/raw.php?o=44887\&p=attachment (accessed: 21.02.2018).

Billingsley S. (2010). The post-communist fertility puzzle // Population Research and Policy Review. 29(2): 193-231.

Buzu A., V. Lutenco (2016). Are we up to the task? Assessment report of the National Strategic Programme on Demographic security 2011-2025. Chisinau: 95.

Fokkema T., A. Liefbroer (2008). Trends in living arrangements in Europe: Convergence or divergence? // Demographic Research. 19(36): 1351-1418. 
Frejka T. (2008). Overview Chapter 5: Determinants of family formation and childbearing during the societal transition in Central and Eastern Europe. Demographic research volume. 9(7): 139-170. URL: http://www.demographic-research.org/Volumes/Vol19/7/ DOI: 10.4054/DemRes.2008.19.7 (accessed: 22.01.2018).

Frejka T. (2012). The role of contemporary childbearing postponement and recuperation in shaping period fertility trends // Comparative Population Studies. 36(4): 927-957.

Frejka T., T. Sobotka (2008). Overview Chapter 1: Fertility in Europe: Diverse, delayed and below replacement // Demographic research. 19(3):15-46. URL: http://www.demographicresearch.org/Volumes/Vol19/3/ DOI: 10.4054/DemRes.2008.19.3. (accessed: 20.12.2017).

Frejka T., S. Zakharov (2014). Evolyutsiya rozhdaemosti v Rossii za polveka: optika uslovnykh i real'nykh pokoleniy [Fertility trends in Russia during the past half century: period and cohort perspectives] // Demograficheskoe obozrenie [Demographic Review]. 1: 106-143.

Gagauz O. (2011). Nizkaya rozhdaemost' v Moldove [Low fertility in Moldova] // Demoscop Weekly [Demoscope Weekly]. 457-458. URL: http://demoscope.ru/weekly/2011/0457/tema01.php (accessed: 10.01.2018).

Gagauz O. (2012). Moldova v protsesse globalizatsii nizkoy rozhdaemosti [Moldova in the process of low fertility globalization] // Demograficheskoe razvitie: vyzovy globalizatsii [Demographic development: challenges of globalization]. Sed'mye Valenteevskie chteniya [The Seventh Valenteevskiye Chteniya]. Mezhdunarodnaya konferentsiya [International conference] (Moscow, Russia, November 15-17 2012) / V.A. Iontsev, ed. Moscow: MAKS Press: 261-270.

Gagauz O. (2013). Moldova na puti vtorogo demograficheskogo perekhoda: strukturnye izmeneniya rozhdaemosti [Moldova on the path of the second demographic transition: structural changes in the birth rate] // Ekonomicheskiy rost v usloviyakh globalizatsii [Economic growth in the conditions of globalization]. Vip.8 [Issue 8]. Materialy mezhdunarodnoy nauchno-prakticheskoy konferentsii, nauchnaya sessiya "Demograficheskoe razvitie: vyzovy dlya sotsial'noy politiki" [Materials of the international scientific-practical conference, scientific session " Demographic development: challenges for social policy"]. (Kishinev, 17-18 okt. 2013): 36-46.

Gagauz O. (2016). Low fertility rate and population decline // Population Situation Analysis in the Republic of Moldova / Gagauz Olga, Stratan A. et al., eds. Chisinau: 63-69. URL: http://ccd.md/en/20-principala-mod/143-population-situation-analysis-in-the-republic-ofmoldova (accessed: 21.12.2017).

HFD (2018). The Human Fertility Database. Max Planck Institute for Demographic Research (Germany) and Vienna Institute of Demography (Austria). URL: www.humanfertility.org (data downloaded on 22.04.2018).

Kohler H.-P., F. Billari, J. Ortega (2002). The emergence of lowest-low fertility in Europe during the 1990s. // Population and Development Review. 28(4): 641-681.

Kuijsten A. (1996). Changing family patterns in Europe: a case of divergence // European Journal of Population. 12(2): 115-143.

McDonald P. (2008). Very low fertility consequences, causes and policy approaches // The Japanese Journal of Population. 6(1). URL: http://www.ipss.go.jp/webjad/WebJournal.files/Population/2008_4/02mcdonald.pdf (accessed: 10.12.2017).

Myrskylä M., J. Goldstein, Y.-H.A. Cheng (2013). New cohort fertility forecasts for the developed world: rises, falls, and reversals // Population and Development Review. 39(1): 31-56. 
National Centre of Public Health of the Ministry of Health of the Republic of Moldova, United Nations Children's Fund (UNICEF) (2014). 2012 Republic of Moldova Multiple Indicator Cluster Survey MICS, Final Report. Chisinau, Republic of Moldova.

Penina O., D.A. Jdanov, P. Grigoriev (2015). Producing reliable mortality estimates in the context of distorted population statistics: the case of Moldova // MPIDR Working Paper WP2015-011, 35 pages (November 2015). Rostock: Max Planck Institute for Demographic Research.

Perelli-Harris B. (2008). Ukraine: on the border between old and new. Childbearing trends and policies: Country case studies / T. Frejka, J. Hoem, L. Toulemon, eds. Demographic Research. 19:29. 1145-1178.

Rindfuss R.R., M.K. Choe, S.R. Brauner-Otto (2016). The emergence of two distinct fertility regimes in economically advanced countries // Population Research and Policy Review. 35(3): 287-304.

Shcherbakova E.M. (2016). Demograficheskaya situatsiya v stranakh SNG, 2014 god [Demographic situation in the CIS countries, 2014 year] // Demoscop Weekly [Demoscope Weekly]. 675-676. URL: http://demoscope.ru/weekly/2016/0675/barom01.php (accessed: 10.01.2018).

Sobotka T. (2003). Re-emerging diversity: rapid fertility changes in Central and Eastern Europe after the collapse of the communist regimes // Population Journal. 58(4/5):451-485.

Sobotka T. (2008). The diverse faces of the second demographic transition in Europe // Demographic Research. 19(8): 171-224.

Sobotka T. (2011). Fertility in Central and Eastern Europe after 1989: collapse and gradual recovery // Historical Social Research. 36. 2: 246-296.

Sobotka T. (2017). Post-transitional fertility: childbearing postponement and the shift to low and unstable fertility levels // Vienna Institute of Demography Working Paper and Human Fertility Database Research Report VID WP 01/2017 and HFD RR 01/2017: 37.

Zakharov S. (2008). Russian Federation: From the first to the second demographic transition / T. Frejka, J.M. Hoem, T. Sobotka, L. Toulemon, eds. // Childbearing Trends and Policies in Europe. Max Planck Institute for Demographic Research: 907-972.

Zeman K., E. Beaujouan, Z. Brzozowska,T. Sobotka (2018). Cohort fertility decline in low fertility countries: Decomposition using parity progression ratios // Demographic research. 38(25): 651-690.

Zhenshchiny-migranty iz stran SNG v Rossii [Women-migrants from the CIS countries in Russia] (2011) / E.V. Tyuryukanova, ed. Moscow: MAKS Press. 120 p. 